\title{
La selectividad de los emigrantes rurales en la sierra ecuatoriana
}

\author{
Richard Bilsborrow y Richard Fuller*
}

\begin{abstract}
En este trabajo se examinan las características de personas recién emigradas de hogares rurales de la región de la sierra ecuatoriana hacia áreas urbanas. Se utiliza una encuesta de hogares cuyo foco es específicamente la migración interna. Esto permite tabulaciones cruzadas por sexo y combinaciones de origen-destino, y provee información acerca de los emigrantes que generalmente no se encuentra en los censos o en las encuestas más genéricas. Se observan diferencias en características demográficas básicas, razones para migrar, y actividades económicas antes de la mudanza entre emigrantes y no emigrantes. También se observan diferencias en las características de los emigrantes por tipo de lugar de origen y de destino. Esta información es útil para evaluar tanto los determinantes como las consecuencias de la migración interna. Los resultados ilustran el valor de las muestras extensas (y de técnicas de muestreo especializadas para seleccionar hogares con emigrantesj para desagregar informacion sobre emigrantes, en particular, por la presentación de los resultados basados en el tipo geográfico del traslado.
\end{abstract}

\section{Introducción}

Los movimientos migratorios internos constituyen una característica dominante del proceso de desarrollo socioeconómico y de la creciente preocupación de los gobiernos en los países en desarrollo. Una mejor comprensión de los determinantes y consecuencias de la migración interna mejorará nuestro entendimiento de las causas de las crecientes presiones en los servicios públicos en las áreas urbanas, tales como la educación, los servicios de salud, el transporte, los programas de empleo y bienestar y, en general, los presupuestos gubernamentales urbanos. La importancia de la migración interna ha sido reafirmada recientemente en el World Monitoring Report donde se presentan las respuestas de los gobiernos a la última investigación de Naciones Unidas respecto al punto de vista oficial de los gobiernos sobre los fenómenos de población en cada país (UN, 1985), y en la Conferencia Mundial de Población de 1984 en la ciudad de México, en donde se le dio un especial énfasis.

Dada la importancia de la migración interna, es sorprendente la falta de encuestas adecuadas sobre el tema. El propósito de este trabajo es el

\footnotetext{
* Deseamos agradecer a John Cook, Sherrie Kossoudji, Thomas McDevitt y Peter Peek sus útiles sugerencias; lo mismo al Instituto Nacional de Estadística y Censos de Ecuador y a la Organización Internacional del Trabajo por permitirnos el uso de sus datos. También estamos agrade cidos por el apoyo financiero de NICHD núm. HD17276-02, núm. 2 T32 HD07186-06 de NICHD/NRSA, y del Carolina Population Center.
} 
de utilizar una encuesta de migración interna, muy extensa y especializada, para proveer información al menos sobre cuatro aspectos de migración y su relación al desarrollo en un lugar particular:

1. ¿Cuáles son las características de los emigrantes por edad, sexo, educación y estado civil marital (características demográficas básicas), y cómo varían entre migrantes masculinos y femeninos?

2. ¿Cómo difieren los emigrantes y no emigrantes con respecto a características demográficas básicas, y cómo varían estas diferencias entre hombres y mujeres?

3. ¿Cuál es la situación de empleo de los emigrantes antes y después de la migración y cuáles son las razones dadas para la mudanza? ¿Cómo varían por sexo?

4. ¿Difieren las características demográficas básicas de los emigrantes rurales de acuerdo al tipo de su destino? ¿A su vez, están estas características asociadas con la situación de empleo antes y después de la migración y las razones para migrar? ¿Varían estas últimas por el tipo de destino? ¿Varían las diferencias en las características básicas, situación de empleo y razones para la migración, por sexo, en los diferentes tipos de destino?

Aunque los datos de censos nos ofrecen a menudo información referente a los puntos 1 y 2 , es raro que los censos sean ejecutados por encuestadores entrenados adecuadamente o a través de preguntas lo suficientemente detalladas como para identificar emigrantes o no emigrantes en forma precisa. Es también prácticamente imposible para los censos obtener información confiable con respecto a los puntos 3 y 4 . A pesar de que algunas encuestas sobre migración en países en desarrollo han recolectado alguna información referente al punto 3 (para una reseña, véase Bilsborrow et al., 1984, cap. 4), no hay ninguna que, a nuestro entender, se haya basado en una muestra que cubriera una área extensa de un país y usara una muestra lo suficientemente grande como para permitir la desagregación que se requiere para los puntos 1, 2, y 4 .

\section{Características del diseño de la encuesta de Ecuador}

La Encuesta de Migración de 1977-1978 en Ecuador se llevó a cabo con el propósito de estudiar la migración rural-urbana en las diez provincias de la sierra ecuatoriana. El estudio fue único en el sentido de llevar a cabo dos encuestas extensas y por separado en áreas rurales y urbanas para identificar a los migrantes y no migrantes tanto en las áreas de origen como en las de destino. Los emigrantes en las áreas rurales se definieron como aquellos individuos de doce años o más que se mudaron de un hogar particular dentro de los cinco años anteriores a la encuesta. La restricción de cinco años fue adoptada para asegurarse de que a) los movimientos mi- 
gratorios investigados fueran recientes y, por lo tanto, de mayor interés, y b) que la calidad de datos fuera razonablemente confiable, dados los problemas para recordar mayor tiempo (Som, 1973). La información referente a estos emigrantes se obtuvo de los miembros del hogar restantes (usualmente el jefe de hogar). En las áreas urbanas los inmigrantes recientes fueron identificados y contestaron preguntas por separado, relevantes a sus mudanzas. Aquí estudiamos solamente la encuesta en las áreas rurales.

Se utilizó en las áreas rurales un muestreo estratificado de tres etapas para obtener suficientes hogares con emigrantes recientes y con significativas extensiones de tierra (Bilsborrow et al., 1984, pp. 127-129; Lasprilla, 1978). En la primera etapa, 90 parroquias rurales (la unidad administrativa más pequeña en Ecuador) fueron seleccionadas, con un sobre-muestreo de parroquias con "alta"1 emigración. En la segunda etapa, dos sectores censales de cada parroquia (cada uno con 60 hogares, aproximadamente) fueron seleccionados al azar, dejando un marco de muestreo de unos 10800 hogares. Finalmente, en la tercera etapa, se seleccio naron hogares del marco de muestreo de tal forma que aquellos con emigrantes o con propiedades de cinco o más hectáreas fueron sobremuestreados. El resultado es una muestra final de más de 3400 hogares y 19000 individuos, incluyendo 3143 emigrantes muy recientes -un número singular para una encuesta especializada de migración en un país en desarrollo.

Como la información de la encuesta fue obtenida de hogares que quedaron en las áreas de origen, se refiere en su mayoría a las características de los emigrantes individuales y no a las de los hogares emigrantes. ${ }^{2}$ Es probable que esto tenga varios efectos en las características de los emigrantes identificados en la encuesta: es más probable que sean jóvenes y solteros que la totalidad de la población de emigrantes rural-urbanos o de emigrantes de áreas rurales en general. El obtener información de otros miembros del hogar por medio del entrevistado "proxy" (normalmente los emigrantes no estaban presentes) también puede dar como resultado unos datos de poca calidad. Sin embargo, el definir a los emigrantes como personas que se trasladan lejos de su hogar en los cinco años anteriores debería reducir considerablemente este problema y asimismo el problema de e rrores de memoria por parte de los que proveen información en representación de la persona ausente. Es crucial recordar este límite de tiempo

\footnotetext{
1 Tabulaciones especiales del censo nacional de 1974 se obtuvieron para poder estimar la propensión de migrar de todas las parroquias rurales en la sierra a las capitales provinciales de la sierra. Las parroquias con tasas de emigración que sobrepasaban de $20 \%$ en los cinco a ños anteriores a la encuesta se estratificaron como si tuviesen tasas "altas".

${ }^{2} \mathrm{O}$ sea, no se recolectó información en los casos en donde todo el hogar se trasladó en los cinco años del periodo de referencia. De hecho, estos datos no se podrían obtenier confiablemente, pues la información sobre varios asuntos básicos proveída v. gr., por vecinos anter iores (aun si no están físicamente lejos) o por parientes es invariablemente dudosa.
} 
y contrastarlo con los datos usuales de censos/encuestas de migración, basadas en migrantes de por vida. Además, un efecto del diseño de la muestra es que el esquema de ponderación para seleccionar hogares en la tercera fase se concentraba en emigrantes rural-urbonos. Esto redujo la muestra de emigrantes rural-rurales en los resultados presentados más adelante, pues fueron muestreados implícitamente usando la misma fracción que para los no emigrantes. Sin embargo, el que las observaciones estén o no ponderadas tuvo muy poco efecto en la distribución de las características. (Véase el Anexo, que reproduce partes relevantes de los primeros dos cuadros del texto, usando datos sin ponderar.]

\section{Características demográficas básicas de los emigrantes rural-urbanos en la sierra ecuatoriana}

La información básica se presenta en las tres columnas izquierdas del cuadro 1: todos los datos se refieren a la población de doce años o más en el momento de migrar (considerados como "adultos"). Recordando ciertos sesgos relacionados con la edad y el estado marital (véase la sección II), observamos que los emigrantes tienden a ser bastante jóvenes, más a menudo hombres que mujeres, con niveles educativos moderados, y predominantemente solteros. Estos resultados no son sorprendentes y son, en general consistentes con la información de los censos sobre emigrantes en muchos países de América Latina, incluyendo Ecuador. La única excepción es la predominancia de hombres en el flujo de emigración a las áreas urbanas, pues generalmente, en los datos de los censos se ha reportado que la razón de masculinidad de emigrantes rural-urbanos es menor que 1.0 en la mayor parte de América Latina. Puede ser que se deba a que los padres (la mayoría de los emigrantes individuales son hijos) están menos inclinados a decir (o admitir) que sus hijas han emigrado a la ciudad; que jóvenes inmigrantes masculinos en áreas urbanas sean subreportados en los censos (como hasta en los censos de EE.UU. y otros); o que la razón es en realidad mayor que 1.0 en la sierra rural ecuatoriana. ${ }^{3}$ Más adelante, en nuestras conclusiones, nos referiremos a la selectividad por sexo.

Si observamos el sexo y la edad al mismo tiempo, encontramos que hay más mujeres que hombres en los tres grupos de edad más jóvenes, y menos en los tres mayores, con la mitad de las mujeres emigrantes de sólo 12-19 años, comparado con $43 \%$ de los hombres. En todo caso, la distribu-

\footnotetext{
${ }^{3}$ De hecho, datos inéditos del Censo de Población de Ecuador de 1982 revelan una razón entre sexos mayor de 1 para emigrantes en la región de la sierra de Ecuador (en contraste con otras regiones). Esta información se basa en la comparación del lugar de residencia actual con el de nacimiento, que por supuesto, no delimita el tiempo para la mudanza. También se refiere a toda la población y no sólo a aquellos de doce años o más. Véase conade (1987).
} 
CUADRO 1

Características demográficas básicas de los adultos rurales emigrantes y no emigrantes en la sierra ecuatoriana, 1977

\begin{tabular}{|c|c|c|c|c|c|c|}
\hline & \multicolumn{3}{|c|}{ Emigrantes } & \multicolumn{3}{|c|}{ No-emigrantes } \\
\hline & Totol & Hombres & Mujeres & Total & Hombres & Mujeres \\
\hline \multicolumn{7}{|l|}{ Grupo de edad } \\
\hline $12-14$ & 11.3 & 10.1 & 13.0 & 11.4 & 12.3 & 10.4 \\
\hline $15-19$ & 34.2 & 32.5 & 36.5 & 16.3 & 17.4 & 15.1 \\
\hline $20-24$ & 25.2 & 24.9 & 25.5 & 10.4 & 10.2 & 10.6 \\
\hline $25-29$ & 10.6 & 11.1 & 9.8 & 7.3 & 6.7 & 7.9 \\
\hline $30-39$ & 11.4 & 12.8 & 9.4 & 14.0 & 12.6 & 15.5 \\
\hline $40+$ & 7.3 & 8.6 & 5.6 & 40.7 & 40.9 & 40.5 \\
\hline Total N & 2958 & 1729 & 1229 & 11158 & 5545 & 5612 \\
\hline \multicolumn{7}{|l|}{ Sexo } \\
\hline Hombres & 58.5 & & & 49.7 & & \\
\hline Mujeres & 41.5 & & & 50.3 & & \\
\hline Total N & 2958 & & & 11157 & & \\
\hline \multicolumn{7}{|l|}{ Educación } \\
\hline Ninguna & 5.0 & 4.8 & 5.3 & 20.2 & 15.0 & 25.3 \\
\hline 1-3 años & 18.4 & 15.5 & 22.6 & 25.9 & 25.4 & 26.5 \\
\hline $4-5$ & 20.1 & 18.9 & 21.9 & 20.2 & 21.2 & 19.2 \\
\hline 6 & 44.0 & 48.9 & 37.0 & 25.9 & 29.7 & 22.2 \\
\hline $7-9$ & 5.9 & 5.0 & 7.3 & 5.1 & 5.5 & 4.7 \\
\hline $10+$ & 6.5 & 6.9 & 5.9 & 2.7 & 3.3 & 2.1 \\
\hline Total N & 2922 & 1707 & 1215 & 11098 & 5514 & 5583 \\
\hline \multicolumn{7}{|l|}{ Estado marital } \\
\hline Soltero & 69.7 & 71.8 & 66.6 & 42.2 & 45.7 & 38.8 \\
\hline Unión consensual & 28.7 & 26.9 & 31.4 & 2.3 & 2.2 & 2.4 \\
\hline Casado & 0.8 & 0.6 & 1.1 & 49.5 & 48.3 & 50.8 \\
\hline Otro & 0.8 & 0.7 & 1.0 & 5.9 & 3.8 & 8.1 \\
\hline Total N & 2954 & 1728 & 1226 & 11050 & 5540 & 5609 \\
\hline
\end{tabular}

ción por edad parece ser aun más joven que la reportada generalmente en los censos y encuestas de migración. Es una creencia muy generalizada que varias de las muchachas de 12-19 años se van solteras a las áreas urbanas en busca de trabajo como sirvientas, al menos en un principio.

Sorprendentemente, mientras había pocos emigrantes sin instrucción, casi $40 \%$ de los hombres y $50 \%$ de las mujeres no había terminado la primaria. El nivel educativo de las mujeres emigrantes rural-urbanas era menor que el de los emigrantes masculinos, al menos en parte como consecuencia de las diferencias educacionales por sexo prevalecientes en las áreas rurales (véase más adelante).

Con respecto al estado marital, aunque la mayoría de los emigrantes son solteros (como es de esperar, dada la estructura de la encuesta, y como fue señalado anteriormente en la sección II), existe un gran número de per- 
sonas que participan en uniones consensuales. Como las uniones consensuales indican una relación de cohabitación, los datos proporcionados sugieren que estos emigrantes (generalmente hijos del entrevistado) fueron a menudo reportados como si se hubiesen ido con el cohabitante, probablemente de la misma área y aproximadamente al mismo tiempo. Aunque las uniones consensuales son comunes en Ecuador, de acuerdo con datos de varios censos y encuestas anteriores, son mucho más prevalentes en la región de la costa que en la sierra. Por lo tanto, lo que aquí hemos encontrado es fascinante y sorprendente. Sugiere que aun dentro de la sierra existe una tendencia común para parejas rurales jóvenes a vivir juntos en una unión consensual por algún tiempo antes de casarse legalmente (por lo civil o por la iglesia). ${ }^{4}$

IV. Comparaciones de las características demográficas básicas de los emigrantes y los no emigrantes

Las tres columnas derechas del cuadro 1 presentan los datos básicos de los no emigrantes y pueden ser comparados con los de los emigrantes. Antes de que entremos a comparaciones directas, es tranquilizador notar que la distribución por edad-sexo de la población no emigrante está razonablemente cercana a la de la población rural en su totalidad (en los censos de 1974 y 1982). Esto nos proporciona alguna certeza de que la calidad de los datos básicos en la encuesta son lo suficientemente buenos para hacer las comparaciones en este trabajo.

En este contexto, examinemos primero la edad. Los emigrantes evidentemente tienden a ser mucho más jóvenes que los no emigrantes, con la proporción entre 15-29 años, y especialmente, entre 15-24, mucho mayor que la de los no emigrantes, particularmente entre las mujeres. Una manera muy sencilla de examinar la concentración relativa de emigrantes comparada con la de los no emigrantes en un grupo en particular, consiste en comparar la razón de las proporciones de emigrantes con la de no emigrantes. ${ }^{5}$ Cuando esta razón de "concentración" es mayor que 1 , indica que los emigrantes predominan (en términos relativos solamente); e inversamente, cuando es menor que 1 . Asimismo, cuando la razón es mayor que 2, podría decirse que indica una fuerte concentración relativa de emigrantes, y viceversa cuando es menor que 5. Por lo tanto los emigrantes

4 En este contexto surge una interrogante: ¿se fugan juntos y luego regresan al hogar maternal a formalizar el matrimonio con la bendición de los padres, o formalizan su relación en la ciudad?

${ }^{5}$ Las diferencias también pueden ser examinadas con la chi cuadrada, diferencias de promedios, o análisis de tests de varianza, pero esto sugería una precisión "cientifica" artificial y complicaría la presentación aqui, que se pretende sea de naturaleza descriptiva. 
están concentrados especialmente en los grupos de edad de 15-24 y mucho más entre las mujeres de 15-19. Con respecto al sexo, la emigración se concentra más entre hombres, como se señaló anteriormente.

Pasando a la educación, las razones de emigrantes y no emigrantes son menores que 1 para ocho de los nueve grupos de bajo nivel educativo por sexo y mayor que 1 para ocho de los nueve grupos de alto nivel educativo por sexo. Esto nos muestra una clara tendencia de los emigrantes a concentrarse en grupos de mayor educación. Yendo más lejos, es extremadamente raro que los emigrantes no tengan instrucción alguna (razones menores de $1 / 3$ para ambos sexos) y mucho más común que tengan diez años o más de educación (razones mayores que 2, aunque los números absolutos son pequeños): el porcentaje de emigrantes con educación primaria completa (en el momento del traslado, según lo recordado por ellos) es 61 para emigrantes masculinos y 31 para hombres no emigrantes; las cifras correspondientes a las mujeres son 50 y 29 . Por lo tanto las diferencias educacionales entre emigrantes y no emigrantes son grandes para ambos sexos, aunque el nivel educativo de las mujeres en áreas rurales era aun menor que el de hombres en el momento de la encuesta. (Las diferencias por sexo en educación han disminuido en los siguientes años, pari passu con la revolución educativa general en el país -véase Bilsborrow y Foley, en prensa.)

Finalmente, en cuanto al estado marital, se esperaba que fuese más posible que los emigrantes fuesen solteros, lo que se observa en el cuadro. La alta proporción de los no emigrantes casados también es de esperar, y contrasta con el alto porcentaje de uniones consensuales entre los emigrantes. Mucha de esta diferencia se debe a las diferencias por edad y la etapa concomitante del ciclo de vida de los dos grupos, recordando que la mayoría de los emigrantes observados en esta encuesta son individuos jóvenes y no de hogares enteros de emigrantes.

V. Actividades antes y después de la migración y razones para la emigración

Es particularmente importante recordar aquí que la información sobre la razón principal para emigración se obtiene de un miembro del hogar diferente al emigrante. Usualmente él es el jefe de hogar (padre del emigrante), que sugiere la posibilidád de ciertos sesgos. Primero, puede haber un sesgo hacia la indicación de las razones puramente económicas en vez de las no económicas o razones personales (como "no aguanto al viejo" o para lograr liberarse de la familia y costumbres conservadoras en las áreas rurales). Existe un segundo sesgo que es más posible y consiste en la subenumeración del trabajo de emigrantes femeninas (generalmente hijas del 
entrevistado), particularmente antes de que dejaran el hogar rural. En las áreas rurales de América Latina, un hombre cuya esposa tiene que ayudar en el trabajo para mantener a la familia, es visto a menudo como menos fuerte o menos "macho". El subregistro del trabajo femenino, especialmente en las áreas rurales de América Latina y otras regiones en desarrollo, ha sido documentado recientemente en censos y encuestas (Anker, 1983; Wainerman y Recchini, 1981), aun si es reportado por las mujeres mismas. Desafortunadamente, no hay bases para medir este sesgo, pero parece mucho menor en los datos de esta encuesta que en los datos censales (véase más adelante).

Recordando estos posibles sesgos, observamos que $2 / 3$ de los emigrantes masculinos reportan haber estado trabajando antes de irse, en contraste con sólo $1 / 4$ de las emigrantes femeninas. Es más, de los que no estaban trabajando, entre los hombres, la mitad se dice que buscaban trabajo o eran trabajadores familiares no remunerados mientras que la otra mitad se dice que estaba estudiando. Esto sugiere un motivo económico muy fuerte para la migración, aun para los que no estaban trabajando. Entre las hijas, de las que no estaban trabajando, sólo $9 \%$ se dice que estaban buscando trabajo o eran trabajadoras familiares no remuneradas (de hecho, evidencia de subreporte, pues la mayoría de las hijas jóvenes hacen varios tipos de trabajo en la granja) y sólo 1/4 decían estar estudiando. Se dijo que 2/3 participaban sólo en "tareas domésticas", i.e., ayudando a su madre en el hogar. ${ }^{6}$ Aunque tenemos la certeza de que esta última cifra es exagerada, también es cierto que las muchachas jóvenes generalmente tienen oportunidades de trabajo bien limitadas en las áreas rurales, tanto en la granja o como trabajadoras asalariadas en granjas cercanas. Hay, por lo tanto, una fuerte sospecha de que los motivos económicos son importantes también para la emigración de las hijas.

Esta suposición encuentra más apoyo en respuestas a las últimas dos preguntas en el cuadro 2, referente al porcentaje de emigrantes que se dice están trabajando ahora (en el momento de la encuesta) y los motivos para dejar el hogar del área de origen. Para los hombres, el porcentaje que estaba trabajando aumentó de 67 antes de la migración, a 86 "ahora", mientras que para las mujeres, el aumento fue de 24 a 53. Esta última cifra para las mujeres podría compararse con las tradicionalmente bajas tasas de participación en la fuerza de trabajo de 25 (urbana) y 11 (rural) observadas para mujeres de doce años o más en el censo de 1982.

Finalmente, con respecto a las razones declaradas por las que emigraron, como era de esperar, difieren también por sexo, con $72 \%$ de los emigrantes masculinos de los que se fueron por motivos económicos versus $52 \%$ de las mujeres (que es aún un porcentaje bastante alto). Nótese

${ }^{6}$ En el censo de 1982 la cifra comparable para mujeres y niñas de doce años o más es de 71 por ciento. 


\section{CUADRO 2}

Motivos para salir y actividad principal de los emigrantes antes y después de salir, sierra ecuatoriana, 1977

\begin{tabular}{|c|c|c|c|}
\hline & Totol & Hombres & Mujeres \\
\hline \multicolumn{4}{|l|}{$\begin{array}{l}\text { ¿Estuvo trabajando } \\
\text { antes de salir? }\end{array}$} \\
\hline Si & 48.8 & 66.6 & 23.7 \\
\hline Total N & 2944 & 1724 & 1220 \\
\hline \multicolumn{4}{|l|}{$\begin{array}{l}\text { Si no, ¿cuál fue la } \\
\text { actividad principal? }\end{array}$} \\
\hline \multicolumn{4}{|l|}{ Trabajador } \\
\hline familiar sin pago & 8.1 & 12.0 & 2.3 \\
\hline Buscando trabajo & 17.9 & 35.2 & 6.8 \\
\hline Asistencia a escuela & 32.2 & 46.0 & 23.5 \\
\hline Quehacer doméstico & 42.4 & 4.2 & 67.0 \\
\hline Otra & 1.3 & 2.3 & 0.4 \\
\hline Total N & 1538 & 600 & 938 \\
\hline \multicolumn{4}{|l|}{$\begin{array}{l}\text { ¿Está trabajando } \\
\text { ahora? }\end{array}$} \\
\hline Si & 72.2 & 85.6 & 53.0 \\
\hline Total N & 2775 & 1633 & 1142 \\
\hline \multicolumn{4}{|l|}{$\begin{array}{l}\text { Motivo para salir de } \\
\text { aqui }\end{array}$} \\
\hline Trabajo o ingreso & & & \\
\hline insu ficiente & 63.5 & 71.9 & 51.6 \\
\hline Educación & 15.4 & 15.0 & 16.0 \\
\hline Amigos o parientes & 9.8 & 3.6 & 18.7 \\
\hline Otro & 11.3 & 9.6 & 13.7 \\
\hline Total N & 2932 & 1718 & 1214 \\
\hline
\end{tabular}

que esto se refiere en su mayoría a razones para la emigración de gente joven, y que la predominancia de razones económicas tanto para hijas como para hijos refleja probablemente los efectos de grandes aumentos en los niveles educativos $y$, por lo tanto, en aspiraciones asociadas de trabajo. También ha habido una reducción considerable en las diferencias por sexo en los niveles educativos en todo el país, incluso en áreas rurales (Bilsborrow y Foley, en prensa; iNEC, 1985).

VI. Cómo difieren los emigrantes en las características demográficas básicas con respecto al tipo de origen y al tipo de destino

El propósito de esta sección es el de examinar las diferencias en las características demográficas básicas de los flujos de emigrantes de la sierra ecua- 
toria na de acuerdo al tipo de origen y al tipo, de destino. Es, por lo tanto, una extensión de la sección iv tratada anteriormente, pero examinando solamente las características de los flujos de emigrantes. Después de examinar las características básicas, extendemos la discusión a examinar las diferencias entre los sexos por tipo de origen y tipo de destino.

El lector deberá recordar que pocas veces es posible, con cualquier encuesta de hogares, reconocer diferencias en las características de los flujos migratorios. En esta encuesta esto fue posible dado que 1) era una encuesta especializada cuyo foco era precisamente la migración, con un número relativamente grande de hogares, y 2) utilizó un diseño de muestreo en que los hogares con emigrantes fueron sobremuestreados, resultando en un número mucho mayor de emigrantes (recientes) que el que se hubiese obtenido si se hubiese usado una muestra aleatoria típica.

Primero comentaremos sobre la selección de los tipos de combinaciones de origen-destino (véase lista al pie de cuadros 3-8). Ecuador puede ser dividido en tres regiones: la sierra, la costa y la selva oriental amazónica. Prácticamente toda la población vive en las regiones de la sierra y de la costa, distribuyéndose aproximadamente en partes iguales. Al mismo tiempo, cada región tiene sólo una ciudad grande: Quito, la capital y centro administrativo del país, en la provincia serrana de Pichincha, y Guayaquil, el centro industrial y puerto principal en la provincia costeña de Guayas. De acuerdo a los censos de 1974 y 1982, las provincias de Pichincha y Guayas continuaban siendo los mayores centros de atracción de emigrantes de otras provincias del país, principalmente como resultado de poseer los dos principales centros urbanos. Cada uno atrae, en su mayoría, emigrantes de su propia región, por varias razones (topografía, diferencias raciales y étnicas, clima, etc.). Por lo tanto, la mayoría de la migración rural-urbana de hogares en la sierra ecuatoriana es hacia otras provincias en la sierra, especialmente Pichincha (Quito) y en un menor grado, hacia la región costera, principalmente Guayaquil. Por consiguiente, hemos escogido los seis flujos indicados. El primero, de Pichincha rural a Pichincha urbana, es en su mayoría migración de corta distancia a Quito. La segunda es migración de otras provincias en la sierra, mayormente hacia Quito (pero desde mayor distancia). El tercer flujo es similar al segundo en cuanto a que es rural-urbano dentro de la sierra, pero es hacia destinos urbanos diferentes de Quito/Pichincha. Estas migraciones usualmente implican mudanzas de distancias más pequeñas que el promedio observado en 2 , pues son principalmente trasladados a la capital de provincia local o canton (distrito). El cuarto flujo es hacia un área diferente de la sierra, casi sismprs a la Costs y usualmente a Guayaquil. ${ }^{7}$ El quinto es

${ }^{7}$ A pesar de que el censo de 1982 señala una tendencia reciente entre los emigrantes a dejar la sierra por el Oriente, éste es un fenómeno bastante reciente (principalmente posterior a 1977) e involucra números absolutos pequeños. 
aquel de emigrantes rurales de la sierra a cualquier destino rural, ya sea en la sierra, costa u oriente. Las bajas cifras reflejan claramente el hecho de que el diseño de la muestra pretendía sobremuestrear hogares con emigrantes rural-urbanos. Y por último, la sexta categoría se refiere a los números relativamente pequeños de emigrantes hacia otros países, probablemente en su mayoría a Colombia y Venezuela. ${ }^{8}$

Los cuadros 3-5, entonces, muestran las diferencias en las características de los flujos migratorios de la sierra por combinaciones de origendestino. Usamos la columna "todos los emigrantes adultos" como grupo de comparación para mostrar cómo los emigrantes de y hacia regiones particulares difieren del promedio. Debemos recordar una vez más que los datos se refieren a emigrantes individuales en situaciones en que el hogar de origen se quedó en el área rural.

Al observar las diferencias por edad vemos en un principio que los emigrantes locales a Quito (columna 1) son sin duda los más jóvenes entre los diferentes flujos. Estos emigrantes, usualmente de corta distancia, aparentemente incluyen a muchos que deciden mudarse en vez de viajar diaria o semanalmente a Quito. Obsérvese que los que se mudan a los destinos más lejanos (en el caso extremo, a otros países, columna 6), son los de mayor edad. Un total de $60 \%$ de los emigrantes tienen sólo 12-19 años (en columna 1) versus $40 \%$ (en columna 4) de los emigrantes sierra-costa, tal vez debido al costo económico de la migración última (más fácil de financiar para un adulto). Es interesante notar que la distribución por edad de los emigrantes rural-rurales, columna 5, es similar a la de la columna 4, aunque ligeramente mayor. Ésta también encierra a emigrantes trasladándose en su mayoría a provincias distantes, ya sea dentro de la sierra, oriente o la costa. Finalmente, las distribuciones por edad en las columnas 2 y 3 son muy similares, sugiriendo que los flujos migratorios urbanos tienen patrones de edad similares dentro de la sierra, sea o no hacia Quito.

Al examinar las diferencias por sexo, encontramos que los traslados de corta distancia (columnas 1 y 3 ) tiene números similares de hombres y mujeres, mientras que los traslados largos son predominantemente masculinos (por ejemplo: las columnas 4 y 6 son $70 \%$ hombres). Esto es también consistente con otros estudios de migración, aunque basados en datos menos adecuados.

Pasando al estado marital, encontramos que la migración local y el otro flujo a Quito (columnas 1 y 3) incluyen a un mayor número de emigrantes solteros, mientras que los que se mudan a lugares más distantes

\footnotetext{
${ }^{8}$ De los 2958 emigrantes adultos, 30 emigrantes con origen en Pichincha y destino en otra provincia de la sierra no fueron incluidos en nuestro esquema de clasificación, y 71 emigrantes fueron excluidos debido a códigos incompletos de destino. El tamaño de la muestra (N) reportado en todos los cuadros señala también con exactitud dónde habia otros datos incompletos. Evidentemente, esto no genera mayor inquietud.
} 


\section{CUADRO 3}

Diferencias en las características de emigrantes adultos rurales en la sierra ecuatoriana según tipo de destino, 1977

\begin{tabular}{|c|c|c|c|c|c|c|c|}
\hline & \multirow{2}{*}{$\begin{array}{c}\text { Emigrantes } \\
\text { adultos }\end{array}$} & \multicolumn{6}{|c|}{ Origen - Combinación de destino } \\
\hline & & 1 & 2 & 3 & 4 & 5 & 6 \\
\hline \multicolumn{8}{|l|}{ Grupo de edad } \\
\hline $12-14$ & 11.3 & 17.9 & 11.4 & 13.1 & 8.3 & 4.8 & 1.5 \\
\hline $15-19$ & 34.2 & 40.9 & 35.7 & 33.9 & 31.1 & 30.6 & 14.7 \\
\hline $20-24$ & 25.2 & 21.4 & 26.5 & 25.0 & 26.1 & 22.5 & 39.7 \\
\hline $25-29$ & 10.6 & 8.2 & 10.3 & 10.9 & 11.2 & 11.4 & 14.7 \\
\hline $30-39$ & 11.4 & 8.0 & 9.5 & 10.3 & 13.7 & 18.1 & 16.2 \\
\hline $40+$ & 7.3 & 3.7 & 6.6 & 6.8 & 9.5 & 12.6 & 13.2 \\
\hline Total $\mathrm{N}$ & 2958 & 487 & 910 & 604 & 517 & 271 & 68 \\
\hline \multicolumn{8}{|l|}{ Sexo } \\
\hline Hombres & 58.5 & 55.2 & 59.0 & 49.0 & 69.4 & 56.1 & 69.1 \\
\hline Mujeres & 41.5 & 44.8 & 41.0 & 51.0 & 30.6 & 43.9 & 30.9 \\
\hline Total $N$ & 2958 & 487 & 910 & 604 & 517 & 271 & 68 \\
\hline \multicolumn{8}{|l|}{ Educación } \\
\hline Ninguna & 5.0 & 3.7 & 6.3 & 3.7 & 4.7 & 6.0 & 2.9 \\
\hline 1-3 años & 18.4 & 24.3 & 17.7 & 13.1 & 16.7 & 25.2 & 11.8 \\
\hline $4-5$ & 20.1 & 16.7 & 22.6 & 17.6 & 21.1 & 25.6 & 11.8 \\
\hline 6 & 44.0 & 46.5 & 41.2 & 48.8 & 46.5 & 36.8 & 44.1 \\
\hline $7-9$ & 5.9 & 5.6 & 5.1 & 8.8 & 4.5 & 3.4 & 13.2 \\
\hline $10+$ & 6.5 & 3.3 & 7.1 & 8.0 & 6.5 & 3.0 & 16.2 \\
\hline Total $\mathrm{N}$ & 2922 & 486 & 901 & 601 & 508 & 266 & 68 \\
\hline \multicolumn{8}{|l|}{ Estado marital } \\
\hline Soltero & 69.7 & 76.0 & 74.0 & 70.4 & 70.8 & 43.9 & 54.4 \\
\hline Unión consensual & 28.7 & 24.0 & 23.4 & 28.5 & 28.2 & 52.4 & 44.1 \\
\hline Casado & 0.8 & 0.0 & 1.5 & 0.3 & 0.4 & 2.2 & 0.0 \\
\hline Otro & 0.8 & 0.0 & 1.1 & 0.8 & 0.6 & 1.5 & 1.5 \\
\hline Total $\mathrm{N}$ & 2954 & 487 & 910 & 604 & 517 & 271 & 68 \\
\hline \multicolumn{8}{|c|}{$\begin{array}{l}\text { 1. Pichincha, rural .............................................. - Pichincha, urbano. } \\
\text { 2. Otra provincia de la sierra, rural..................... Pichincha, urbano. } \\
\text { 3. Otra provincia de la sierra, rural................. otra provincia de la sierra, urbano. } \\
\text { 4. Cualquier provincia de la sierra, rural............... otra provincia de Ecuador, urbano. } \\
\text { 5. Cualquier provincia de la sierra, rural............. - cualquier provincia de Ecuador, rural. } \\
\text { 6. Cualquier provincia de la sierra, rural............... - país extranjero (urbano o rural). }\end{array}$} \\
\hline
\end{tabular}

(a la costa o al extranjero) tienen un mayor número de personas en uniones consensuales.

Dada la relevancia de la educación como una medida de capital humano, es especialmente importante observar las características educacionales de los flujos de emigrantes como un indicador de los flujos de capital humano que ejercen gran influencia en los cambios relativos de la capacidad productiva de las regiones de origen y destino en el país. Vemos 
que la migración local o de corta distancia (columna 1) involucra a los emigrantes rural-urbanos con la menor instrucción; esto es consistente con otros estudios y con la teoría de capital humano de migración. Es decir, aquellos con altos niveles de instrucción tienen un mejor conocimiento acerca de los destinos alternativos y encuentran que sus habilidades son cotizadas en un contexto de mercado de trabajo más amplio geográficamente (aun nacional). ${ }^{9}$ También observamos que otros flujos migratorios rural-urbanos dentro de la sierra incluyen a individuos con niveles educativos un poco más altos que el promedio. Los pequeños grupos de emigrantes internacionales tiene los niveles educativos más altos de todos, lo que sugiere que ellos son mucho más que simple goteo de campesinos pobres hacia fronteras de países vecinos; son más bien movimientos de personas relativamente bien instruidas. Finalmente, los flujos migratorios ruralrurales involucran, como es de esperarse, a las personas con los menores niveles educativos.

Ahora consideraremos las diferencias por sexo. Esto se puede hacer comparando primero las cifras dentro de cada cuadro ( 4 y 5) por combinaciones de origen-destino, y luego entre los dos cuadros. Nos concentramos en este último para minimizar la redundancia de la discusión de "todos los adultos" del cuadro 3 presentada anteriormente. Primero, con respecto a la edad, como fue visto, los jóvenes migrantes (12-19 años) dominan los flujos hacia Quito. Éstos son traslados predominantemente de corta distancia y en su inmensa mayoría de mujeres (por cierto, más de $68 \%$ de las mujeres emigrando hacia Quito tenían entre 12 y 19 años), aunque la juventud es también característica de los hombres en la columna 1. En la otra cara de la moneda, los emigrantes masculinos mudándose a la costa (columna 4) son mayores que las mujeres emigrantes, con la diferencia considerablemente mayor para emigrantes rural-rurales $(35 \%$ de los hombres mayores de treinta años versus $25 \%$ de las mujeres) y los emigrantes internacionales ( $36 \%$ de los hombres mayores de treinta años versus $14 \%$ de las mujeres).

En contraste, hay muy poca diferencia entre los sexos por estado marital en las varias combinaciones de origen-destino (no asombra pues "se necesitan dos para bailar un tango"). Las principales diferencias observadas son: a) para emigrantes rural-rurales, en donde hay una mayor proporción de solteros entre hombres, y de uniones consensuales entre mujeres; ${ }^{10}$ b) para emigración de larga distancia fuera de la sierra en donde se encuentran más hombres solteros.

\footnotetext{
${ }^{9}$ Exactamente el mismo razonamiento sustenta la aun mayor selectividad educacional de los emigrantes internacionales que tienden a tener niveles educacionales universitarios. Sin embargo, los datos disponibles son deformados por requisitos de preferencia con respecto a la admisión de los inmigrantes.

10 Esto es en parte consecuencia de un mayor número absoluto para los hombres: el total de la muestra en uniones consensuales es de 59 y 83 .
} 
Finalmente, la composición educativa de los flujos migratorios ruralurbanos hacia Quito o a cualquier otro lugar dentro de la sierra no difieren significativamente por sexo (considerando que generalmente el número absoluto de hombres es ligeramente mayor). Pero para la emigración de la sierra a la costa, y especialmente los flujos migratorios internacionales fuera de la sierra, el nivel educativo de las mujeres es ligeramente mayor que el de los hombres. Esto podría sugerir que las mujeres, para trasladarse largas distancias, requieren mayores niveles educacionales, ya sea para que las motiven a dar este gran paso (riesgo), o para esperar ganancias económicas significativas de un mejor empleo.

\section{CUADRO 4}

Diferencias en las características de emigrantes adultos rurales en la sierra ecuatoriana según tipo de destino; hombres, 1977

\begin{tabular}{|c|c|c|c|c|c|c|c|}
\hline & \multirow{2}{*}{$\begin{array}{c}\text { Emigrantes } \\
\text { hombres }\end{array}$} & \multicolumn{6}{|c|}{ Origen - Combinación de destino } \\
\hline & & 1 & 2 & 3 & 4 & 5 & 6 \\
\hline \multicolumn{8}{|l|}{ Grupo de edad } \\
\hline $12-14$ & 10.1 & 13.4 & 9.3 & 14.7 & 8.4 & 5.9 & 0.0 \\
\hline 15-19 & 32.5 & 37.6 & 36.3 & 30.2 & 29.5 & 29.6 & 12.8 \\
\hline 20-24 & 24.9 & 21.9 & 27.0 & 25.7 & 26.5 & 19.7 & 34.0 \\
\hline $25-29$ & 11.1 & 11.9 & 10.5 & 12.1 & 10.6 & 9.9 & 17.0 \\
\hline 30-39 & 12.8 & 11.2 & 10.3 & 9.9 & 14.2 & 19.1 & 19.2 \\
\hline $40+$ & 8.6 & 4.1 & 6.6 & 7.4 & 10.9 & 15.8 & 17.0 \\
\hline Total N & 1729 & 269 & 515 & 272 & 359 & 152 & 47 \\
\hline \multicolumn{8}{|l|}{ Educación } \\
\hline Ninguna & 4.8 & 3.4 & 5.5 & 3.0 & 4.5 & 7.4 & 4.3 \\
\hline 1-3 años & 15.5 & 21.2 & 16.1 & 10.3 & 12.4 & 22.2 & 12.8 \\
\hline $4-5$ & 18.9 & 15.6 & 21.8 & 15.1 & 19.8 & 24.8 & 17.0 \\
\hline 6 & 48.9 & 52.0 & 45.3 & 55.4 & 51.7 & 38.9 & 42.6 \\
\hline $7-9$ & 5.0 & 5.2 & 2.8 & 7.8 & 4.5 & 3.4 & 8.5 \\
\hline $10+$ & 6.9 & 2.6 & 8.6 & 8.5 & 7.1 & 3.4 & 14.9 \\
\hline Total N & 1707 & 269 & 510 & 271 & 354 & 149 & 47 \\
\hline \multicolumn{8}{|l|}{ Estado marital } \\
\hline Soltero & 71.8 & 74.4 & 76.3 & 71.3 & 74.9 & 57.2 & 48.9 \\
\hline Unión consensual & 26.9 & 25.6 & 21.4 & 28.3 & 24.2 & 38.8 & 51.1 \\
\hline Casado & 0.6 & 0.0 & 1.2 & 0.0 & 0.3 & 2.6 & 0.0 \\
\hline Otro & 0.7 & 0.0 & 1.2 & 0.4 & 0.6 & 1.3 & 0.0 \\
\hline Total N & 1728 & 269 & 515 & 272 & 359 & 152 & 47 \\
\hline
\end{tabular}

1. Pichincha, rural ................................................. Pichincha, urbano.

2. Otra provincia de la sierra, rural............................. - Pichincha, urbano.

3. Otra provincia de la sierra, rural......................... otra provincia de la sierra, urbano.

4. Cualquier provincia de la sierra, rural................ otra provincia de Ecuador, urbano.

5. Cualquier provincia de la sierra, rural.................. - cualquier provincia de Ecuador, ru.ral.

6. Cualquier provincia de la sierra, rural................. país extranjero (urbano o rural). 
CUADRO 5

Diferencias en las características de emigrantes adultos rurales en la sierra ecuatoriana según tipo de destino; mujeres, 1977

\begin{tabular}{|c|c|c|c|c|c|c|c|}
\hline & \multirow{2}{*}{$\begin{array}{c}\text { Emigrantes } \\
\text { mujeres }\end{array}$} & \multicolumn{6}{|c|}{ Origen - Combinación de destino } \\
\hline & & 1 & 2 & 3 & 4 & 5 & 6 \\
\hline \multicolumn{8}{|l|}{ Grupo de edad } \\
\hline $12-14$ & 13.0 & 23.4 & 13.9 & 11.7 & 8.2 & 3.4 & 4.8 \\
\hline $15-19$ & 36.5 & 45.0 & 35.4 & 37.0 & 34.8 & 31.9 & 19.1 \\
\hline $20-24$ & 25.5 & 20.6 & 26.8 & 25.3 & 25.3 & 26.1 & 52.4 \\
\hline $25-29$ & 9.8 & 3.7 & 9.7 & 10.7 & 12.7 & 13.5 & 9.5 \\
\hline $30-39$ & 9.4 & 4.1 & 7.8 & 10.4 & 12.7 & 16.8 & 9.5 \\
\hline $40+$ & 5.6 & 3.2 & 6.4 & 4.9 & 6.3 & 8.4 & 4.8 \\
\hline Total N & 1229 & 218 & 373 & 308 & 158 & 119 & 21 \\
\hline \multicolumn{8}{|l|}{ Educación } \\
\hline Ninguna & 5.3 & 4.2 & 7.8 & 3.9 & 5.2 & 4.3 & 0.0 \\
\hline 1-3 años & 22.6 & 28.1 & 20.3 & 16.6 & 26.6 & 29.1 & 9.5 \\
\hline $4-5$ & 21.9 & 18.0 & 24.3 & 21.2 & 24.0 & 26.5 & 0.0 \\
\hline 6 & 37.0 & 39.6 & 34.1 & 41.7 & 34.4 & 34.2 & 47.6 \\
\hline $7-9$ & 7.3 & 6.0 & 8.1 & 9.1 & 4.6 & 3.4 & 23.8 \\
\hline $10+$ & 5.9 & 4.2 & 5.4 & 7.5 & 5.2 & 2.6 & 19.1 \\
\hline Total N & 1215 & 217 & 370 & 307 & 154 & 117 & 21 \\
\hline \multicolumn{8}{|l|}{ Estado marital } \\
\hline Soltero & 66.6 & 78.0 & 71.1 & 70.3 & 61.4 & 26.9 & 66.7 \\
\hline Unión consensual & 31.4 & 22.0 & 25.7 & 27.9 & 37.3 & 69.8 & 28.6 \\
\hline Casado & 1.1 & 0.0 & 2.1 & 0.7 & 0.6 & 1.7 & 0.0 \\
\hline Otro & 1.0 & 0.0 & 1.1 & 1.3 & 0.6 & 1.7 & 4.8 \\
\hline Total N & 1226 & 218 & 373 & 308 & 158 & 119 & 21 \\
\hline
\end{tabular}

1. Pichincha, rural .................................................. Pichincha, urbano.

2. Otra provincia de la sierra, rural........................ - Pichincha, urbano.

3. Otra provincia de la sierra, rural.......................... otra provincia de la sierra, urbano.

4. Cualquier provincia de la sierra, rural.............. - otra provincia de Ecuador, urbano.

5. Cualquier provincia de la sierra, rural................. cualquier provincia de Ecuador, rural.

6. Cualquier provincia de la sierra, rural................... país extranjero (urbano o rural).

VII. Diferencias en las características de los flujos migratorios con respecto a las actividades antes y después de la migración y razones para la emigración de acuerdo al tipo de origen y destino

Esta sección es esencialmente análoga a la sección $v$ anterior, pero examina las diferencias en los flujos migratorios de acuerdo a varias combinaciones de origen y destino. Los cuadros 6-8 presentan los resultados. Dada la plétora de números, los discutiremos más resumidamente que como en la sección v. Repetimos el proceso de primero distinguir las características de los flujos migratorios de acuerdo al tipo de origen-destino (cuadro 6) para luego regresar a examinar las diferencias por sexo más adelante. 
CUADRO 6

Diferencias en los motivos y actividad económica de los emigrantes adultos rurales en la sierra ecuatoriana según tipo de destino, 1977

\begin{tabular}{|c|c|c|c|c|c|c|c|}
\hline & \multirow{2}{*}{$\begin{array}{l}\text { Emigrantes } \\
\text { adultos }\end{array}$} & \multicolumn{6}{|c|}{ Origen - Combinación de destino } \\
\hline & & 1 & 2 & 3 & 4 & 5 & 6 \\
\hline \multicolumn{8}{|l|}{$\begin{array}{r}\text { ¿Estuvo trabajando } \\
\text { antes de salir? }\end{array}$} \\
\hline Sí & 48.8 & 44.2 & 51.3 & 42.8 & 51.1 & 53.7 & 58.8 \\
\hline Total N & 2944 & 486 & 907 & 601 & 517 & 270 & 68 \\
\hline \multicolumn{8}{|c|}{$\begin{array}{l}\text { Si no, ¿cuál fue la } \\
\text { actividad principal? } \\
\text { Trabajador }\end{array}$} \\
\hline familiar sin pago & 6.1 & 7.4 & 6.7 & 4.8 & 4.7 & 5.6 & 3.6 \\
\hline Buscando trabajo & 17.9 & 27.9 & 15.3 & 11.9 & 21.2 & 13.5 & 25.0 \\
\hline Asistencia a escuela & 32.2 & 26.2 & 33.9 & 43.5 & 29.0 & 15.1 & 39.3 \\
\hline Quehacer doméstico & 42.4 & 38.2 & 43.5 & 38.7 & 41.6 & 63.5 & 32.1 \\
\hline Otra & 1.3 & 0.4 & 0.7 & 1.1 & 3.5 & 2.4 & 0.0 \\
\hline Total N & 1538 & 283 & 446 & 354 & 255 & 126 & 28 \\
\hline \multicolumn{8}{|l|}{$\begin{array}{l}\text { ¿Está trabajando } \\
\text { ahora? }\end{array}$} \\
\hline Sí & 72.2 & 79.3 & 75.0 & 59.8 & 76.1 & 64.9 & 81.5 \\
\hline $\begin{array}{l}\text { Total } N \\
\text { Motivo para salir de } \\
\text { aquí }\end{array}$ & 2775 & 469 & 868 & 560 & 486 & 259 & 65 \\
\hline Trabajo o ingreso & & & & & & & \\
\hline insuficiente & 63.5 & 73.5 & 66.6 & 50.0 & 67.1 & 53.0 & 75.0 \\
\hline Educación & 15.4 & 14.0 & 14.1 & 26.8 & 12.1 & 6.3 & 10.3 \\
\hline Amigos o parientes & 9.8 & 4.7 & 8.3 & 12.5 & 10.5 & 18.5 & 10.3 \\
\hline Otro & 11.3 & 7.8 & 10.9 & 10.7 & 10.3 & 22.2 & 4.4 \\
\hline Total N & 2932 & 487 & 905 & 598 & 513 & 270 & 68 \\
\hline
\end{tabular}

1. Pichincha, rural...

2. Otra provincia de la sierra, rural.

Pichincha, urbano.

- Pichincha, urbano.

3. Otra provincia de la sierra, rural...................... - otra provincia de la sierra, urbano.

4. Cualquier provincia de la sierra, rural.................. otra provincia de Ecuador, urbano.

5. Cualquier provincia de la sierra, rural................. cualquier provincia de Ecuador, rural.

6. Cualquier provincia de la sierra, rural............... país extranjero (urbano o rural).

A primera vista, observamos que entre los emigrantes de corta distancia (columnas 1 y 3), encontramos el menor número de los que trabajaban antes de la mudanza, mientras que entre los emigrantes rural-rurales e internacionales se halla el número mayor de éstos. Pero las diferencias no son tan grandes como se esperaba. De los que no trabajaban, el mayor número de personas que asistían a la escuela lo encontramos entre los que emigraron al extranjero y entre los que emigraron de otras provincias de la sierra hacia otros destinos urbanos serranos (larga distancia). Entre los 
emigrantes rural-rurales encontramos, como era de esperar, el menor número de personas que asistían a la escuela. Entre los que se mudaron a Quito dentro de Pichincha y, quizá sorprendentemente, entre los emigrantes internacionales, encontramos un mayor número de gente trabajand o antes de la mudanza. Esto último podría sugerir que estas personas tenían relativamente altas aspiraciones de trabajo que no fueron satisfechas dentro de su área local (rural). ${ }^{11}$ Los que se mudaron a Quito incluyen a muchos en busca de trabajo por primera vez, como fue sugerido por los datos de edad en el cuadro 3. Nótese que también es cierto que los porcentajes más altos de emigrantes actualmente trabajando (o sea, en el momento de la encuesta), están entre los mismos dos grupos de origen-destino; entre los emigrantes de otras áreas rurales serranas a otras áreas urbanas serranas, y entre los emigrantes rural-rurales, encontramos el menor número de gente trabajando en la actualidad. Esto último podría reflejar dificultades para encontrar empleo rural en el nuevo lugar de destino o deseos de asistir a la escuela. Más adelante veremos cuál de estos dos es más factible.

Al comparar los porcentajes de personas trabajando antes del traslado versus en el momento de la encuesta, el mayor aumento es para los que se mudaron de Pichincha rural a Quito, seguido de los flujos de otros lugares de la sierra a Quito y de otros lugares de la sierra a la costa [columna 4). Esto podría sugerir que los emigrantes rurales tuvieron más exito en encontrar trabajo en las dos ciudades grandes que en otros lugares, lo que explicaría el continuo poder de atracción de las ciudades, observado posteriormente en el censo de 1982. Por otro lado, hubo poco aumento en el porcentaje de gente actualmente trabajando entre los que se mudaron a otras áreas rurales, lo que sugiere que la población tuvo dificultades para conseguir trabajo. Desde luego, ésta fue nuestra interpretación inicial pero más tarde nos dimos cuenta de que era incorrecta. Primero, nótese que para los hombres señalados en la columna 5 (cuadro 7), existen altos niveles de los que trabajaban, no sólo antes sino también después del traslado, refutando nuestra hipótesis de las dificultades para encontrar trabajo en el destino rural. Segundo, quienes son reportados como no habiendo aumentado su prevalencia de participación laboral (cuadro 8, columna 5) son las mujeres emigrantes rural-rurales, en contraste con sus contrapartes rural-urbanas. Hemos observado anteriormente que los bajos porcentajes de mujeres rurales reportados como "trabajando" representan subestimaciones serias. Este ejemplo ilustra, por lo tanto, lo fácil que es hacer inferencias incorrectas de datos que agregan a ambos sexos y, por consiguiente, lo importante que es desagregar la información por sexo.

${ }^{11}$ Estas aspiraciones podrían estar relacionadas con los altos niveles de educación, y posiblemente de bienes familiares. Esto último podría, por supuesto, ayudarles en las mudanzas de larga distancia. Pero estas especulaciones están abusando del tamaño tan pequeño de la muestra. 
Finalmente, con respecto a los motivos, como es de esperar basados en lo anterior, las razones económicas parecen dominar entre los emigrantes hacia Quito y entre emigrantes internacionales. La educación (asistir a la escuela) es un motivo para los emigrántes de otras provincias rurales serranas a otras áreas urbanas serranas más que para los otros flujos, mientras que amigos, parientes y razones diversas son más á menudo dadas por los emigrantes rural-rurales (por cierto, constituyen $40 \%$ de las razones reportadas).

\section{CUADRO 7}

Diferencias en los motivos y actividad económica de los emigrantes adultos rurales en la sierra ecuatoriana según tipo de destino; hombres, 1977

\begin{tabular}{|c|c|c|c|c|c|c|c|}
\hline & \multirow{2}{*}{$\begin{array}{l}\text { Emigrantes } \\
\text { hombres }\end{array}$} & \multicolumn{6}{|c|}{ Origen - Combinación de destino } \\
\hline & & 1 & 2 & 3 & 4 & 5 & 6 \\
\hline \multicolumn{8}{|l|}{$\begin{array}{l}\text { Estuvo trabajando } \\
\text { antes de salir? }\end{array}$} \\
\hline Sí & 66.6 & 62.8 & 69.2 & 61.2 & 64.9 & 76.3 & 76.6 \\
\hline Total N & 1724 & 269 & 536 & 294 & 359 & 152 & 47 \\
\hline \multicolumn{8}{|l|}{$\begin{array}{l}\text { Si no, ¿cuál fue la } \\
\text { actividad principal? } \\
\text { Trabajador }\end{array}$} \\
\hline familiar sin pago & 12.0 & 15.3 & 14.1 & 9.1 & 8.7 & 8.3 & 9.1 \\
\hline Buscando trabajo & 35.2 & 50.5 & 30.6 & 25.6 & 35.4 & 38.9 & 45.5 \\
\hline Asistencia a escuela & 46.0 & 31.5 & 49.4 & 58.7 & 44.9 & 41.7 & 45.5 \\
\hline Quehacer doméstico & 4.2 & 1.8 & 4.1 & 4.1 & 5.5 & 5.6 & 0.0 \\
\hline Otra & 2.6 & 0.9 & 1.8 & 2.5 & 5.5 & 5.6 & 0.0 \\
\hline Total N & 600 & 111 & 170 & 121 & 127 & 36 & 11 \\
\hline \multicolumn{8}{|l|}{$\begin{array}{c}\text { ¿Está trabajando } \\
\text { ahora? }\end{array}$} \\
\hline Sí & 85.6 & 90.4 & 85.8 & 72.9 & 88.2 & 92.5 & 93.2 \\
\hline Total N & 1633 & 259 & 515 & 277 & 340 & 147 & 44 \\
\hline \multicolumn{8}{|l|}{$\begin{array}{l}\text { Motivo para salir de } \\
\text { aquí } \\
\text { Trabajo o ingreso }\end{array}$} \\
\hline insuficiente & 71.9 & 80.3 & 73.8 & 57.3 & 73.6 & 70.9 & 87.2 \\
\hline Educación & 15.0 & 12.6 & 13.5 & 27.1 & 12.9 & 8.6 & 8.5 \\
\hline Amigos o parientes & 3.6 & 1.5 & 2.8 & 4.1 & 5.3 & 5.3 & 0.0 \\
\hline Otro & 9.6 & 5.6 & 9.9 & 11.5 & 8.2 & 15.2 & 4.3 \\
\hline Total N & 1718 & 269 & 535 & 295 & 356 & 151 & 47 \\
\hline
\end{tabular}


Ahora, considerando las diferencias por sexo (cuadros 7 y 8), entre los hombres que partieron hacia el extranjero o hacia otras áreas rurales, encontramos el mayor número que había trabajado antes de la mudanza, aunque las diferencias son pequeñas. Entre las mujeres, las diferencias en la situación de empleo previa a la migración también son pequeñas; entre aquellas que se mudaron a las áreas urbanas no serranas (en su mayoría a Guayas) o hacia el extranjero, encontramos el menor número de mujeres que había trabajado antes del traslado.

\section{CUADRO 8}

Diferencias en los motivos y actividad económica de los emigrantes adultos rurales en la sierra ecuatoriana según tipo de destino; mujeres, 1977

\begin{tabular}{|c|c|c|c|c|c|c|c|}
\hline & \multirow{2}{*}{$\begin{array}{l}\text { Emigrantes } \\
\text { mujeres }\end{array}$} & \multicolumn{6}{|c|}{ Origen - Combinación de destino } \\
\hline & & 1 & 2 & 3 & 4 & 5 & 6 \\
\hline \multicolumn{8}{|l|}{$\begin{array}{l}\text { ¿Estuvo trabajando } \\
\text { antes de salir? }\end{array}$} \\
\hline Sí & 23.7 & 21.2 & 25.3 & 25.1 & 19.6 & 24.6 & 19.1 \\
\hline Total N & 1220 & 217 & 371 & 307 & 158 & 118 & 21 \\
\hline \multicolumn{8}{|l|}{$\begin{array}{l}\text { Si no, ¿cuál fue la } \\
\text { actividad principal? } \\
\text { Trabajador }\end{array}$} \\
\hline familiar sin pago & 2.3 & 2.3 & 2.2 & 2.6 & 0.8 & 4.4 & 0.0 \\
\hline Buscando trabajo & 6.8 & 13.4 & 5.8 & 4.7 & 7.0 & 3.3 & 11.8 \\
\hline Asistencia a escuela & 23.5 & 22.7 & 24.3 & 35.6 & 13.3 & 4.4 & 35.3 \\
\hline Quehacer doméstico & 67.0 & 61.6 & 67.8 & 56.7 & 77.3 & 86.7 & 52.9 \\
\hline Otra & 0.4 & 0.0 & 0.0 & 0.4 & 1.6 & 1.1 & 0.0 \\
\hline Total $\mathbf{N}$ & 938 & 172 & 276 & 233 & 128 & 90 & 17 \\
\hline \multicolumn{8}{|l|}{$\begin{array}{c}\text { ¿Está trabajando } \\
\text { ahora? }\end{array}$} \\
\hline Sí & 53.0 & 65.7 & 59.2 & 47.0 & 48.0 & 28.6 & 57.1 \\
\hline Total N & 1142 & 210 & 353 & 283 & 146 & 112 & 21 \\
\hline \multicolumn{8}{|l|}{$\begin{array}{l}\text { Motivo para salir de } \\
\text { aquí } \\
\text { Trabajo o ingreso }\end{array}$} \\
\hline insuficiente & 51.6 & 65.1 & 56.2 & 42.9 & 52.2 & 30.3 & 47.6 \\
\hline Educación & 16.0 & 15.6 & 15.1 & 26.4 & 10.2 & 3.4 & 14.3 \\
\hline Amigos o parientes & 9.8 & 8.7 & 16.2 & 20.8 & 22.3 & 35.3 & 33.3 \\
\hline Otro & 13.7 & 10.6 & 12.4 & 9.9 & 15.3 & 31.1 & 4.8 \\
\hline Total N & 1214 & 218 & 370 & 303 & 157 & 119 & 21 \\
\hline $\begin{array}{l}\text { 1. Pichincha, rural........ } \\
\text { 2. Otra provincia de la } \\
\text { 3. Otra provincia de la } \\
\text { 4. Cualquier provincia } \\
\text { 5. Cualquier provincia } \\
\text { 6. Cualquier provincia }\end{array}$ & $\begin{array}{l}\text { rural............. } \\
\text { rural............ } \\
\text { ierra, rural... } \\
\text { ierra, rural... } \\
\text { ierra, rural... }\end{array}$ & & Pichi & $\begin{array}{l}\text { a, ur } \\
\text { a, ur } \\
\text { inci } \\
\text { inci } \\
\text { pro } \\
\text { anjer }\end{array}$ & $\begin{array}{l}\text { o. } \\
\text { o. } \\
\text { la si } \\
\text { Ecu } \\
\text { ia de } \\
\text { Irban }\end{array}$ & $\begin{array}{l}\text {, urb } \\
\text { r, urb } \\
\text { uador } \\
\text { rural }\end{array}$ & iral. \\
\hline
\end{tabular}


Entre los hombres que no estaban trabajando, aproximadamente la mitad de los emigrantes de corta distancia a Quito y los emigrantes internacionales buscaban trabajo antes de la mudanza, pero probablemente por razones diversas: al tomar en cuenta su edad y otras características, es claro que muchos de los primeros buscaban trabajo por primera vez mientras que los últimos ya estaban en el mercado de trabajo y sin empleo o se percibían a sí mismos como subempleados. Por el contrario, sólo un cuarto de los que se mudaron de otras provincias rurales de la sierra a otras urbanas de la sierra estaban buscando trabajo antes de la última mudanza. El otro lado de la moneda es que el porcentaje de estos últimos que asistía a la escuela antes del traslado era casi dos veces tan alto como el de los emigrantes de Pichincha-Quito.

Como era de esperar, los porcentajes de mujeres reportadas como trabajando antes del traslado son mucho menores que los de los hombres. Lo mismo ocurre con los porcentajes de los que buscaban trabajo y los que no estaban trabajando. Las diferencias absolutas en porcentajes son mayores para los emigrantes rural-rurales, que no es sorprendente. Entre las mujeres que no estaban trabajando antes, los mismos dos grupos de origen-destino (que para los hombres) también tuvieron los más altos porcentajes de mujeres que buscaban trabajo (columnas 1 y 6), y la misma columna 3 tuvo el más alto porcentaje de las que asistían a la escuela (36 por ciento). Correspondientemente, los más altos porcentajes reportados en quehaceres domésticos se encuentran en las columnas 4 y 5 , que es de esperar si la hipótesis acerca de los efectos (sesgo) por entrevistar a otro miembro del hogar para recolectar información acerca de la persona ausente es correcta (sección II).

$\mathrm{Al}$ observar el trabajo actual, se reporta que generalmente más de $90 \%$ de los hombres y de $50 \%$ de las mujeres están actualmente trabajando en Quito, áreas urbanas no serranas, el extranjero, y destinos rurales, versus sólo $70 \%$ de los hombres emigrando hacia otros destinos urbanos serranos y $29 \%$ de las mujeres mudándose a otros destinos rurales. Esto no indica necesariamente dificultades para obtener empleo en esos destinos, pues más hombres emigrantes podrían estar en la escuela. (El caso extremo entre las mujeres del grupo 5 ha sido discutido anteriormente.) Esto es en cierta manera confirmado por los motivos reportados para la mudanza, en donde sólo $57 \%$ de este grupo de emigrantes masculinos fueron reportados como habiéndose mudado por razones económicas, comparado con 71 a $87 \%$ para las otras columnas.

Es interesante que los motivos económicos para la mudanza figuren como los principales entre hombres y mujeres emigrantes a Quito (columnas 1 y 2), y menos entre emigrantes rural-rurales. La educación fue la razón dada más a menudo, igualmente para ambos sexos, para las mudanzas de otras provincias rurales serranas a otras provincias urbanas serranas, $y$ prácticamente inexistente entre los emigrantes rural-rurales. Esto era de 
esperar, dada la escasez de servicios educacionales en muchas áreas rurales más allá de unos cuantos primeros años de la primaria.

\section{Discusión y conclusiones}

Antes de considerar las conclusiones generales de un volumen tan amplio de evidencia cuantitativa, se debe tratar primero un punto metodológico general: para poder distinguir significativamente las diferencias en las características de los flujos migratorios de datos de encuestas de hogares, la encuesta debería a) enfocarse en la migración interna, y b) utilizar técnicas especializadas de muestreo para obtener un extenso número de emigrantes recientes. La palabra "reciente" está deliberada e íntimamente relacionada con a) y b): si se está interesado solamente en emigrantes de vida, entonces a) y b) no son necesarios en muchos países. Pero la información acerca de los emigrantes de por vida es de poco valor para los gobiernos (o aun para los investigadores) preocupados con las causas y consecuencias de la migración reciente, pues no fija la mudanza en el tiempo o la edad, y solamente ve el traslado "neto" de por vida (que desaparece por completo en el caso de la migración neta de retorno). Por lo tanto, en la encuesta que aquí hemos analizado, se utilizó un límite de cinco años en la definición de "emigrante (reciente)". Los que emigraron hace más de cinco años son incluidos aquí en las columnas para "no emigrantes".

Con respecto a las conclusiones primordiales en un principio discutimos las características de los emigrantes comparadas con las de los no emigrantes, luego las diferencias entre hombres y mujeres emigrantes, y por último, las diferencias en las características de los emigrantes dejando la sierra rural de acuerdo a su lugar de origen y destino. Debemos recordar que el análisis no incluye a todos los flujos migratorios en Ecuador, aunque si cubre a una región principal que constituye cerca de la mitad del país. Específicamente, la emigración de áreas rurales a la costa, la migración urbana-urbana, y los más recientes flujos al oriente (aunque cuantitativamente pequeños) no son incluidos.

Algunos de los resultados pueden ser comparados con los de otros países encontrados en estudios anteriores; la mayoría se ha basado solamente en datos censales y, por lo tanto, cubre sólo diferencias básicas de emigrantes-no emigrantes. El hecho de que los emigrantes difieran de los no emigrantes fue observado ya en 1938 por Thomas (para los EE.UU.), y está claramente implícito en las "leyes" de Ravenstein $(1885,1886)$. Resúmenes más recientes se encuentran en Browning (1971), Elizaga (1972), Shry ock y Siegel (1973, cap. 21), UN (1973), Findley (1977), Bilsborrow et al. (1984), etc. En la discusión más adelante no entramos en detalle en cómo difieren nuestras conclusiones de estos informes anteriores; solo señalamos los hallazgos sorprendentes y derivamos implićaciones generales. 
Primero, examinando las características de los emigrantes versus las de los no emigrantes, encontramos que los emigrantes son más jóvenes, más educados y entre ellos se hallan más solteros que entre los no emigrantes (todo esto consistente con la literatura). Normalmente, a todo esto se le llama selectividad "positiva", pues entre los más educados, más jóvenes, y por presunción más capaces, se encuentran más emigrantes en busca de mejores oportunidades en otra parte: los niveles educacionales de los emigrantes rurales son mayores que los de la población no emigrante, con $56.4 \%$ de emigrantes rurales versus sólo $33.7 \%$ de los no emigrantes rurales que habían completado seis o más años de educación. Esto asciende a una "fuga de cerebros" significativa en las áreas rurales, y tiene también el efecto irónico de reducir los niveles promedio de educación de ambos, origen rural y áreas urbanas de destino, porque la población urbana residente tenía un nivel educacional sustancialmente mayor que el promedio (con $78.2 \%$ habiendo completado la primaria, de acuerdo a la encuesta urbana paralela de migración en la sierra en 1977-1978).

Pero en Ecuador se observa una diferencia entre emigrantes y no emigrantes que difiere del punto de vista usual de América Latina: casi 3/5 de la muestra de emigrantes son hombres, mientras que la literatura comúnmente afirma que la migración hacia las áreas urbanas en América Latina es predominantemente femenina, en contraste con otras regiones en el Tercer Mundo (Browning, 1978:287; United Nations, 1973:181 y 182; Connell, et al., 1976:43; Findley, 1977:13; Orlansky y Dubrovsky, 1978:6 y 7; Kols, 1983:256). Pero estos estudios se basan principalmente en encuestas sobre sólo el área de destino, que son más útiles para estudiar los diferenciales de migración y no la selectividad migratoria (Elizaga, 1971:140). Claramente, nuestra muestra representativa de (individuos) emigrantes rurales no es directamente comparable con las muestras de inmigrantes urbanos basadas solamente en una ciudad o en unas cuantas ciudades como en las encuestas urbanas. El estudio de Schultz sobre la migración rural-urbana en Colombia es uno de los pocos en reconocer esto; con respecto al tema de la selectividad por sexo él afirma: "la emigración rural no es marcadamente selectiva por sexo, pero la inmigración urbana es un tanto selectiva de mujeres" (Schultz, 1970:5). La selectividad masculina aquí observada se confirma en Ecuador para los emigrantes de la sierra rural en el censo de 1982 (INEC, 1985).

Seguidamente, aunque la mayoría de las características de los emigrantes y no emigrantes eran similares entre los sexos, se confirmaron algunas diferencias. Especificamente, los hombres emigrantes tendfan a ser un tanto mayores de edad, mejor educados, y solteros (a pesar de que son mayores) que entre las mujeres emigrantes. Se observa una diferencia mayor entre los porcentajes que estaban trabajando o buscando empleo antes de la mudanza (más de $3 / 4$ para los hombres, comparado con más de 1/4 para las mujeres), que hemos atribuido en parte al subregistro del 
trabajo femenino, como se señaló en el texto y en estudios recientes. Distinciones en las definiciones que involucran a trabajadores a medio tiempo, trabajadores familiares no remunerados, y trabajadores domés ticos no son muy claras y podrían contribuir a las diferencias más visibles. Sin embargo, es intrigante que se reportara que más de la mitad de ambos (mujeres y hombres) emigrantes se habían mudado por razones económicas ("no había suficiente trabajo" o "no tenían suficientes ingresos").

Finalmente, la desagregación de emigrantes entre varias com binaciones de origen-destino nos permite comparar emigrantes rural-rur ales con los rural-urbanos, emigrantes de corta y larga distancia, y emigrantes a ciudades pequeñas y grandes. Encontramos que la distancia era un factor importante en la selectividad por sexo: la selectividad masculina er a mayor en las mudanzas de larga distancia desde otras provincias hacia Pichincha y hacía provincias no serranas y al extranjero, mientras que las mujeres constituían la mayoría de los emigrantes hacia áreas urbanas más pequeñas dentro de la sierra. El tipo de destino también resultó significativo al examinar el estado marital, pues entre los emigrantes a destinos urbanos en Pichincha (ya fuese de distancias largas o cortas) se encontraban más solteros que entre los emigrantes a áreas rurales y áreas urbanas más pequeñas.

Tanto la distancia como el tipo de destino resultaron importantes al examinar la selectividad por edad y los motivos para la migración. Los emigrantes más jóvenes eran aquéllos mudándose a las áreas urbanas dentro de Pichincha, mientras que los mayores eran los que migraron (de retorno) a destinos rurales. Entre los emigrantes de corta distancia a Quito (dentro de la provincia) encontramos mayores razones económicas para la mudanza que entre los que migraron una corta distancia hacia áreas urbanas más pequeñas.

Finalmente, la desagregación de emigrantes entre diferentes categorías de origen-destino por sexo ofrece algunas implicaciones sobre los efectos de una economía agraria en la selectividad migratoria. A pesar de que la razón entre sexos para los emigrantes rural-rurales no era tan alta como la de los otros grupos de emigrantes (de nuevo, al contrastarlo con los estudios sobre la migración en América Latina), entre los emigrantes a áreas rurales encontramos un mayor porcentaje de hombres que de mujeres que se habían mudado por razones económicas y que habían estado trabajando en la fecha de la encuesta. Esto refleja el hecho de que existen pocas oportunidades de trabajo en las áreas rurales para las mujeres (véanse Orlansky y Dubrovsky, 1978; Herold, 1979).

Una encuesta como ésta, extensa y detallada, sobre migración reciente, nos permite el tipo de desagregación de flujos migratorios por edad, sexo, educación, etc., de acuerdo a las áreas de origen y destino, lo que es de considerable uso potencial para los planificadores gubernamentales. Primero, la información sobre las características de los flujos entre 
áreas puede suplementar la informacion censal usual para asistir en el diseño de proyecciones de población de corto y mediano plazo entre las regiones principales por características detalladas. Segundo, la información sobre las razones dadas puede ser útil para comprender porqué la gente se muda (suplementada por información de estimaciones multivariadas de los determinantes de los flujos migratorios), que es necesario para el desarrollo de políticas para influir movimientos migratorios hacía rumbos más deseables. Por ejemplo, en Ecuador, una de las metas principales declaradas en los dos últimos planes de desarrollo es la de promover la migración a otras ciudades (pequeñas y medianas) en vez de Quito y Guayaquil. Tercero, la información sobre la composición educacional de movimientos recientes de la población entre las diferentes áreas indica el grado en que los problemas de "fuga de cerebros" entre áreas y regiones existen - por ejemplo, del campo hacia áreas urbanas y de una provincia a otra.

Esto es importante en la evaluación de las consecuencias de los movimientos de población y, por lo tanto, en sí la intervención gubernamental es o no deseable. La evidencia sobre este punto es mixta. Por un lado, hay fuerte evidencia de selectividad positiva entre los emigrantes, lo que mejora el surtido de capital humano y la capacidad productiva de las áreas urbanas en general a costa de las áreas rurales. Este agotamiento de la mano de obra productiva en las áreas rurales podría estar contribuyendo al estancamiento de la producción alimentaria en la región de la sierra desde los años setenta, que ha contribuido al aumento en las importaciones de alimentos y problemas con la balanza de pagos. Por otro lado, la selectividad no está sesgada a favor de Quito, la ciudad con los niveles promedio educacionales (y de ingresos, etc.), más altos: otras áreas urbanas parecen estar recibiendo inmigrantes con más instrucción, que la ciudad de Quito.

Una investigación definitiva de las características de los flujos migratorios en la sierra va más allá del alcance de este trabajo pues además requiere información de emigrantes urbano-urbanos y rurales que migran como unidad familiar.

ANEXO:

Resultados ponderados para emigrantes adultos rurales

\begin{tabular}{lrrr}
\hline & Total & Hombres & Mujeres \\
\hline Grupo de edad & & & \\
$12-14$ & 9.8 & 9.3 & 10.4 \\
$15-19$ & 33.8 & 32.8 & 35.2 \\
$20-24$ & 25.2 & 24.1 & 26.9 \\
$25-29$ & 10.1 & 9.8 & 10.5 \\
$30-39$ & 12.2 & 13.4 & 10.5 \\
$40+$ & 8.9 & 10.6 & 6.5 \\
Total N & 2958 & 1729 & 1229
\end{tabular}


ANEXO, continuación

\begin{tabular}{|c|c|c|c|}
\hline & Total & Hombres & Mujeres \\
\hline \multicolumn{4}{|l|}{ Sexo } \\
\hline Hombres & 58.77 & & \\
\hline Mujeres & 41.33 & & \\
\hline Total N & 2958 & & \\
\hline \multicolumn{4}{|l|}{ Educación } \\
\hline Ninguna & 5.5 & 5.3 & 5.8 \\
\hline 1-3 años & 20.5 & 17.9 & 24.1 \\
\hline $4-5$ & 19.4 & 18.1 & 21.3 \\
\hline 6 & 42.5 & 46.8 & 36.4 \\
\hline $7-9$ & 5.6 & 4.9 & 6.5 \\
\hline $10+$ & 6.5 & 7.0 & 5.9 \\
\hline Total N & 2922 & 1707 & 1215 \\
\hline \multicolumn{4}{|l|}{ Estado marital } \\
\hline Soltero & 66.5 & 71.2 & 59.8 \\
\hline Unión consensual & 31.7 & 27.1 & 38.1 \\
\hline Casado & 0.7 & 0.6 & 0.8 \\
\hline Otro & 1.2 & 1.1 & 1.3 \\
\hline Total N & 2954 & 1728 & 1226 \\
\hline \multicolumn{4}{|l|}{$\begin{array}{l}\text { ¿Estuvo trabajando antes } \\
\text { de salir? }\end{array}$} \\
\hline Sí & 50.9 & 67.9 & 26.8 \\
\hline No & 49.1 & 32.1 & 73.2 \\
\hline Total N & 2944 & 1724 & 1220 \\
\hline \multicolumn{4}{|l|}{$\begin{array}{l}\text { Si no, ¿cuál fue la } \\
\text { actividad principal? } \\
\text { Trabajador }\end{array}$} \\
\hline familiar sin pago & 6.1 & 12.4 & 2.0 \\
\hline Buscando trabajo & 15.3 & 31.2 & 4.9 \\
\hline Asistencia a escuela & 31.1 & 44.4 & 22.5 \\
\hline Quehacer doméstico & 44.7 & 7.3 & 69.1 \\
\hline Otra & 2.7 & 4.8 & 1.4 \\
\hline Total N & 1538 & 600 & 938 \\
\hline \multicolumn{4}{|l|}{ ¿Está trabajando ahora? } \\
\hline Sí & 72.2 & 84.3 & 47.3 \\
\hline No & 27.8 & 15.7 & 52.7 \\
\hline Total N & 2775 & 1633 & 1142 \\
\hline \multicolumn{4}{|l|}{$\begin{array}{l}\text { Motivo para salir de } \\
\text { aquí } \\
\text { Trabajo o ingreso }\end{array}$} \\
\hline insuficiente & 63.5 & 71.8 & 47.6 \\
\hline Educación & 15.3 & 15.0 & 15.6 \\
\hline Amigos o parientes & 9.8 & 4.5 & 21.8 \\
\hline Otro & 11.3 & 8.7 & 14.9 \\
\hline Total N & 2932 & 1718 & 1214 \\
\hline
\end{tabular}




\section{Bibliografía}

Anker, R. 1983. "Female Labor Force Participation in Developing Countries: A Critique of Current Definitions and Data Collection Methods. International Labour Review, 122(6): 709-723.

Bilsborrow, R. E., A. S. Oberai y G. Standing. 1984. Migration Surveys in Low-Income Countries. Londres y Sydney: Croom Helm.

Bilsborrow, R. E. y M. Foley, en prensa. La planificación de la educación: un modelo nuevo con un estudio de caso del Ecuador. Quito: Universidad Central.

Browning, H. L. 1971. "Migrant Selectivity and the Growth of Large Cities in Developing Societies", en Rapid Population Growth: Consequences and Policy Implications, compiladores R. Revelle. Baltimore: National Academy of Sciences, Johns Hopkins University Press.

Cardona Gutiérrez, R. (ed.). 1976. Colombia: distribución espacial de la población. Bogotá: Corporación Centro Regional de Población.

Consejo Nacional de Desarrollo (CONADE). 1985. "Diagnóstico socio-demográfico de la población del Ecuador, 1950-1982." Quito: mimeo.

Connell, J., B. Dasgupta, R. Laishley y M. Lipton. 1976. Migration from Rural Areas. Delhi: Oxford University Press.

Elizaga, Juan C. 1972. "Internal Migration: An Overview." International Migration Review 6[2], pp. 121-145.

Findley, Sally. 1977. Planning for Internal Migration. Washington: U.S. Bureau of the Census.

Herold, Joan. 1979. "Female Migration in Chile: Types of Moves and Socioeconomic Characteristics." Demography 16(2), pp. 257-277.

Instituto Nacional de Estadística y Censos (INEC). 1985. IV Censo de población y vivienda, 1982, resultados definitivos. Quito.

Kols, Adrienne. 1983. "Migration, Population Growth, and Development." Population Reports, Serie M, núm 7. Population Information Program, The Johns Hopkins University.

McDevitt, T., R. E. Bilsborrow, S. Kossoudji y R. Fuller. 1985. "A Multilevel Model of Migration from the Ecuadorian Sierra." Documento presentado en: Annual Meetings of the Population Association of America, Boston, Mass.

Orlansky, Dora, and Silvia Dubrovsky. 1978. "The Effects of Rural-Urban Migration on Women's Role and Status in Latin America." UNESCO: Reports and Papers in the Social Sciences, núm. 41.

Ravenstein, E. G. 1885. "The Laws of Migration." lournal of the Royal Statistical Society, 48(2), pp. 167-277.

Schultz, T. Paul. 1970. "Rural-Urban Migration in Colombia." Publicación p-4488. Santa Monica, Calif.: The Rand Corporation.

Som, R. K. 1973. Recall Lapre in Demographic Enquires. New York: Aria Publishing Huose.

United Nations. 1973. The Determinants and Consequences of. Population Trends. Department of Economic and Social Affairs, Population Studies, núm. 50. New York. 1984. World Monitoring Report, 1983. New York.

Wainerman, C. y Z. Recchini de Lattes. 1981. El trabajo femenino en el banquillo de los acusados. La medición censal en América Latina. Mexico City: Terra Nova, para el Population Council. 